dilution techniques, using chromatographic and electrophoretic separations, and further information was obtained on the enzyme content of ribosomes, while the mechanism of protein synthesis was also studied through the amino-acid analogue technique, and considerable information was obtained on the mechanism of amino-acid selection by cells.

In the Department of Plant Biology it has been demonstrated that simultaneous absorption of light by chlorophyll $a$ and chlorophyll $b$ both increases the efficiency of light utilization by chlorophyll $a$ and raises the initial photosynthetic rate after a dark period markedly over a situation when chlorophyll $a$ alone is activated by light. Enhancement effects were also observed from alternate pulsing, in periods of 0.6-15 sec., of light sources of wave-lengths absorbed by chlorophyll $a$ on one hand and chlorophyll $b$ on the other. Studies continued on the characterization of the different forms of chlorophyll $a$ occurring in living plants and additional evidence was sought for the differentiation of the three forms of shlorophyll $a$ through fluorescence spectrography, differential bleaching and in other ways. By highspeed centrifugation in a liquid medium of graded density, protochlorophyll holochrome has been obtained relatively free from blue and ultra-violet absorbing contaminants and the transformation from protochlorophyll to chlorophyll was studied by observ ing the degree of fluorescence of freshly forming chlorophyll. Electron-microscopical studies of etiolated plastids showed that chloroplast lamellæ will form in the absence of protochlorophyll, but the normal aggregation and close pairing of the lamellar disks require the presence of chlorophyll. A bacterial pigment with protochlorophyll-like absorption properties was extracted from a mutant of the purple bacterium, Rhodopseudomonas spheroides. The gathering of essential data for the study of range grass hybrids of $P o a$ is being concluded, and the investigations have revealed principles relating to the synthesis of new forms in apomictic genera by interspecific hybridization. A study on the genetic structure and evolution of the yarrows, members of the polyploid Achillea millefolium complex, is also nearing completion, and studies on rates of photosynthesis and respiration of two altitudinal races of Mimulus cardinalis, one from sea-level near the coast of California and the other at middle altitudes in the Sierra Nevada of California, have shown them to differ in the temperature optima and requirements for light saturation when functioning as intact plants. A device has been installed that can regulate, within a narrow range, the carbon dioxide in the air of a small chamber, thus permitting study of the effects of different concentrations of carbon dioxide on plants and simplifying the control of air temperature and relative humidity. In an analysis of the chromosome constitution of races of maize grown in Chile, Bolivia, Ecuador and Venezuela, a relation was found between the knob pattern and the geographical location of the race, which suggests that, under some conditions, a knowledge of the patterns of distribution based on chromosomal-knob constitution may give valuable evidence of the origins and migrations and past history of some early races of Indian corn.

The Department of Genetics has continued to focus attention on the structural and functional properties of genes and chromosomes, and it now appears that the suppressor-mutator system of control of gene expression in maize has some major resernblances to the system controlling flagellar-antigen formation in Salmonella. Studies of the effects of deoxyribonuclease on unfixed cells have shown that this enzyme enters the living cell and there brings about marked swelling and deformation of chromosomes, sometimes without appreciable loss of deoxyribonucleic acid. Hybrids have been obtained of Salmonella typhimurium and $E$. coli, thus permitting comparison of the homology of their chromosome structure, and the chromosome of the bacteriophage T2 has been shown to consist of deoxyribonucleic acid, while the mechanisms of replication and recombination of genetic material in bacteriophages has also been investigated.

Studies of the synthesis and interaction of specific macromolecules, in the Department of Embryology, have been specially concerned with tissue specificity, and further experiments in immuno-embryology suggest that there may be two stages in the development of the immune response, which may be experimentally separable. Continued study of immune response of new-born rabbits to injections of chicken liver and spleen homogenates suggests that animals not injected at birth respond strongly to a few major antigenic components, whereas the response of the treated experimental group is eliminated or reduced. A study of the effects of thyroxine upon the metamorphosis of visual pigment of the eyes of the bullfrog tadpole afforded substantial support for the view that thyroxine acts directly on a rate-limiting factor in the eye itself. Encouraging results have been obtained in experiments on the inductive ability of tissue microsomes designed to elucidate inconsistencies in embryonic induction, attributed to a failure of ribonucleic acid or ribonucleoprotein to reach its site of action.

\title{
STATUS AND DEVELOPMENT OF THE TEACHING OF CHEMISTRY
}

\begin{abstract}
T the Organization for European Economic Co-operation's Summer School for Science Teachers held in 1958 at Tutzing, Germany, the Teachers held in 1958 at Tutzing, Germany, the secondary schools has changed little since 1900 and secondary schools has chant present descriptive approach to the subject involves much memory work on the part of the student, and displays little of the scientific method. It was agreed that it was urgent that chemistry
\end{abstract}

should be taught from the perspective of present-day theory and that so far as possible modern knowledge should be fed back to the school. As a result of these discussions the Organization for European Economic Co-operation's Office for Scientific and Technical Personnel, which works under the direction of Dr. Alexander King, in co-operation with the Irish Department of Education, organized a seminar at Greystones, Co. Wicklow, during February 28-March 10. 
The objective of the seminar was to consider at a high level the preconditions and possibilities of: (1) a revision of chemistry teaching based on the knowledge of the atom; (2) pruning of the subjectmatter in order to give more time to fundamentals without, however, neglecting adequate experimental work; (3) teaching chemical principles in such a way that they play a part in training the intellect of the pupil. The seminar was asked to come to conclusions concerning the specific steps required to provide the basis for a curriculum more fitted, intellectually and practically, to the needs of modern chemistry.

The following countries were represented at the seminar: Austria, Belgium, Denmark, France, Germany, Greece, Iceland, Ireland, Italy, Luxembourg, Netherlands, Norway, Portugal, Spain, Sweden, Switzerland, Turkey, United Kingdom and United States. The participants comprised senior secondary school teachers of chemistry, those with official responsibility for chemistry programmes (senior officials of education ministries, inspectors of education), representatives of teacher-training institutes, professors of chemistry.

The proceedings were officially opened by $\mathrm{Mr}$. Rafferty, secretary of the Irish Department of Education. Then followed the 'Keystcne Address' of the chairman (Prof. T. S. Wheeler, Dublin). He recapitulated the objectives of the seminar and reviewed the papers to be presented, which were as follows : "Advances in Theoretical Chemistry since 1900" (Prof. K. Grob, Zurich); "The Importance of Molecular Structure in Elementary Chemical Teaching" (Prof. J. Bénard, Paris); "The Requirements for Entry to University Departments of Chemistry" (Prof. W. Cocker, Dublin); "The Requirements for School-leavers entering the Chemical Industry" (Dr. A. K. Mills, Dublin); "The Principles underlying Recent Advances in Practical Chemistry" (Dr. R. J. Magee, Belfast); "The Co-ordination of the Teaching of Chemistry, Physics and Mathematics in Secondary Schools" (Prof. M. Eurin, Paris) ; "The Teaching of Oxidation-Reduction and Acid-Base Reactions in Relation to the Electronic Atom" (Prof. A. Steiger, Zurich); "The Toaching of Chemistry to Students of 14-16 Years" (Dr. K. Stein, Bad Segeberg); "The Teaching of Chemistry to Students of 16-18 Years" (Dr. B. Borén, Stockholm) ; "Pruning and Simplification of the Syllabus and the Teaching of Fundamentals" (Prof. L. E. Strong, Richmond, Indiana); "New Materials and Teaching Aids, Text-books, Films, Models" (Prof. J. A. Campbell, Claremont, California).

The discussions were not confined to the set sessions, but were vigorous throughout the period of the seminar. Tuesday and the morning of Wednesday of the second week wero devoted to the preparation of reports for transmission to the Organization for European Economic Co-operation. Owing to language difficulties, it was necessary to constitute three working parties (English and German; English and French; English or French, simultaneous interpretation). These parties were asked to make recommendations relating to two chemistry courses, one for students of 14-16 years and the other for those of 16-18. It was assumed that some three hours a week would be available for the study of the subject and that there would be facilities for experimental work.

It was realized that among countries conditions differ much as regards school-leaving age, facilities for practical work, time available for chemistry, and qualifications of teachers. In addition, schools have to cater for those who hope to become chemists and for other; who have done with their chemistry when they leave school. Nevertheless it was considered that reports of the type envisaged would be of value to teachers anxious to modernize their courses, who could select to suit their needs.

Each working party had two chairmen (morning and afternoon) who kept in toueh with the chairmer, of other groups to ensure a measure of unity in the three approaches to the problems under consideration, though it was not thought disadvantageous to have three sets of views on the subjects at issue.

The reports were discussed at two plenary sessions of the seminar. It was agreed that the junior student should have his interest developed early in the constitution and properties of matter. Emphasis should be on observation, and formal definitions kept to a minimum. Methods other than the inductive arguments of Dalton should be used to develop the concept of atoms. The importance of space-filling models at all stages of instruction was stressed. The combustion of coke, the interaction of sulphur and copper, and similar systerns can be employed to introduce the notions of chemical reactions, energy change, gaseous, liquid, and plastic systems, chemical equations and structural ideas. It is important that the student understand weight relationships and their correlation to chemical formulæ and equations.

For senior students atomic structure should be the framework of the course and not simply an additional chapter unco-ordinated with the rest of the chemical material presented. The Bohr-Rutherford atom provides a useful introduction; the nature of bonds should be discussed and directional characteristics emphasized. The law of mass action and chemical equilibrium should be treated in terms of reaction kinetics. The Brønsted treatment of acid-base equilibrium is recommended; redox systems can usefully be considered. Reaction mechanisms, thermochemistry and electrochemistry should also be treated in an advanced school course. So far as possible, phenomena should be related to structure; consideration of ion size can be illuminating in the study of crystals. The concept of electronegativity can also be employed to advantage in the discussion of chemical reactions.

Organic chemists should also be taught from the electronic point of view. The nature of single, double and triple bonds should be explained and the reactions of functional groups displayed in relation to their structure. The use of experimental results in the assignment of organic structures provides excellent examples of the application of the scientific method. If time permits, stereoisomerism should be dis. cussed.

In all school courses the collection of a great number of facts about elements and compounds should be avoided. There is no necessity for systematic treatment of elements; examples should be drawn from the chemistry of one or more elements to illustrate a subject, for example redox systems, under discussion. Brief descriptions of technical processes should be introduced where they are of value in illustrating chemical principles. In this connexion reference was made to the tendency for accounts of out-of-date plant to be retained in school text-books. Properly prepared films and film strips can be of great help at all levels of instruction. 
The seminar stressed the necessity for providing teaching of physics and mathematics such that the chemistry student has at all stages a knowledge of these ancillary subjects adequate for his needs. Finally, it was suggested that the Organization for Europəan Economic Co-operation bring the recommendations to the notice of the appropriate authorities in the member countries with a request for comments. After an appropriate time small working parties, constituted similarly to the seminar, should meet in Paris to consider such comments as are received and to prepare manuals outlining school courses in chemistry relating to : $(a)$ lectures; $(b)$ demonstration experiments by teachers; (c) laboratory work by students. The necessity for devising means for training teachers capable of dealing with these new courses should also be considered.

The participants in the seminar felt that their discussion about a new approach to chemistry had been worth while, and that many concrete ideas of practical value had been elaborated.

\section{T. S. WHEELER}

\section{WATER POLLUTION BY TRADE EFFLUENTS}

$\mathrm{T}$ HE last two major Acts in Britain governing the disposal of sewage and industrial effluents were the Public Health (Drainage of Trade Premises) Act of 1937 and the Rivers (Prevention of Pollution) Act of 1951 ; River Boards, which are responsible for controlling the discharge of polluting liquors to rivers, were set up by an Act passed in 1948. During the past few years, some of the provisions of the Acts of 1937 and 1951 have led to much discussion; a committee, under the chairmanship of Sir Frederick Armer, set up by the Central Advisory Water Committee, after hearing evidence from the many interests concerned with pollution of surface waters, has now reviewed the experience of the past twenty years, and has recommended some important changes in the law*.

The Rivers (Prevention of Pollution) Act differentiated between discharges to streams already being made in 1951, and discharges made after that date. A River Board could control existing effluents in either of two ways : it could bring an action againstany. one discharging a "poisonous, noxious, or polluting" liquid, it being left to the Court to decide whether the liquid could be so described, or it could make by-laws (which would require confirmation) covering a stream, or part of a stream, specifying standards of quality with which discharges would have to conform. It had been widely hoped and expected that River Boards would formulate by-laws, at least in industrial areas, since a manufacturer, for example, in designing a plant to treat a polluting liquor, clearly wishes to know the specification of the final effluent he is called on to produce.

It has been found, however, to be very difficult to formulate by-laws, and in fact none has so far been confirmed and come into operation. Since any standards adopted were expected to apply to a considerable length of river, if not to the whole of a river system, the first difficulty was to draw up a specification of permitted effluents which might have to be applied to a wide range of industrial wastes, the composition of which might be unknown, even to the manufacturers, and which might be so complex in composition as to make routine chemical analysis impracticable ; an example would be a liquor arising from the cooling and washing of a town's gas supply. This perhaps could have been overcome by examining liquors of whatever kind by a few comparatively simple tests, each designed to measure the effect of

* Ministry of Housing and Local Government: Central Advisory Water Committee. Final Report of the Trade Effluents Sub-Committe of the Central Advisory Water Committee. H.M. Stationery Office, 1960.) $3 s .6 d$. net. the liquor on some property of a stream. Among those suggested were tests for $p \mathbf{H}$ value, toxicity to fish, and concentration of suspended solids and oxidizable matter. A greater difficulty is that it is impracticable to treat all polluting liquors, particularly industrial liquors, to give effluents of a common standard of quality - a point which, from internal evidence, was clearly in the minds of those who drew up the Act of 1951.

Control of new or altered discharges brought into use after 1951 was, however, effected in a different way. Here a River Board could impose conditions on the nature and composition, and on the volume, of the discharges, each being considered separately. It was thus possible in each case to draw up a specification appropriate to the liquid to be discharged; for example, for a liquor from electroplating, the maximum allowable concentrations of toxic metals and of cyanide would be specified. This machinery has worked very well, and since 1951 agreement has been reached on the conditions of discharge of large numbers of new effluents.

The Committee now recommends that River Boards should be empowered (subject to appeal) to deal with all discharges, whether new or existing, by essentially the same procedure. It was recognized that the improvement of the quality of some rivers, particularly the more heavily polluted of them in industrial areas, will have to be a gradual process. It is proposed, therefore, that a River Board should have powers to impose standards on effluents which could be reviewed later, and, if necessary, made more stringent.

On the question of discharge of industrial wastes to sewers of a local authority, the chief change recommended is that, except where a contract is in force, the authority should now be empowered to make a charge for the treatment of liquors which have been discharged without major change since before 1937; under the Act of 1937 these acquired 'prescriptive rights' and were exempt from payment. All traders would have to furnish information to their local authorities on the volume and nature of effluents discharged to sewers.

The Committee took evidence from all the major interests concerned with the purity of streams and, on all but one matter (the private rights of a riparian owner) have produced a unanimous report, which if implemented by legislation should greatly assist River Boards and local authorities in reducing the level of pollution of rivers in Great Britain. 